\section{Evidence that muscle cells do not express the histidine-rich glycoprotein associated with AMP deaminase but can internalise the plasma protein}

\author{
A.R.M. Sabbatini, ${ }^{1}$ L. Mattii, ${ }^{2}$ B. Battolla, ${ }^{2}$ \\ E. Polizzi, ${ }^{1}$ D. Martini, ${ }^{1}$ M. Ranieri-Raggi, ${ }^{1}$ \\ A.J.G. Moir, ${ }^{3}$ A. Raggi ${ }^{1}$ \\ 'Dipartimento di Scienze dell'Uomo e \\ dell'Ambiente, Chimica e Biochimica \\ Medica, Università di Pisa, Italy; \\ 2Dipartimento di Morfologia Umana e \\ Biologia Applicata, Sezione di Istologia \\ ed Embriologia, Università di Pisa, Italy; \\ ${ }^{3}$ Krebs Institute, Department of \\ Molecular Biology and Biotechnology, \\ University of Sheffield, UK
}

\section{Abstract}

Histidine-rich glycoprotein (HRG) is synthesized by liver and is present at relatively high concentration in the plasma of vertebrates. We have previously described the association of a HRG-like molecule to purified rabbit skeletal muscle AMP deaminase (AMPD). We also provided the first evidence for the presence of a HRG-like protein in human skeletal muscle where a positive correlation between HRG content and total determined AMPD activity has been shown. In the present paper we investigate the origin of skeletal muscle HRG. The screening of a human skeletal muscle cDNA expression library using an anti-HRG antibody failed to reveal any positive clone. The RT-PCR analysis, performed on human skeletal muscle RNA as well as on RNA from the rhabdomyosarcoma (RD) cell line, failed to show any mRNA specific for the plasma HRG or for the putative muscle variant. When the RD cells were incubated with human plasma HRG, a time-dependent increase of the HRG immunoreactivity was detected both at the plasma membrane level and intracellularly. The internalisation of HRG was inhibited by the addition of heparin. The above data strongly suggest that skeletal muscle cells do not synthesize the muscle variant of HRG but instead can actively internalise it from plasma.

\section{Introduction}

The histidine-rich-glycoprotein (HRG), a member of the cystatin superfamily, is a single chain glycoprotein of approximately $75 \mathrm{kDa}$ that is present at a relatively high concentration in the plasma of vertebrates $(100-200 \mu \mathrm{g} / \mathrm{mL}$ in humans). ${ }^{1}$ HRG is a multidomain polypeptide consisting of two cystatin-like regions at the N-terminus, a central histidine-prolinerich region and a C-terminal domain. HRG can bind to a variety of ligands such as fibrinogen, plasminogen, heparin, heparan sulphate, tropomyosin and divalent transition metal cations. Its multidomain structure suggests that the molecule may act as an adaptor protein that can bring together different ligands under specific conditions. The physiological role of HRG is still to be established, although it has been implicated in a number of cellular processes including blood coagulation and fibrinolysis, angiogenesis, immune complex clearance, cell adhesion and cell migration. ${ }^{2}$ HRG is synthesized in parenchymal liver cells, ${ }^{3}$ although some studies have suggested that it may also be produced by immune cells such as monocytes and macrophages ${ }^{4}$ and by megakaryocytes. ${ }^{5}$ The tissue distribution of mouse HRG mRNA, investigated by Northern blot analysis performed on total RNA from liver, spleen, thymus, heart, lung, kidney, brain and testis, demonstrated that HRG mRNA is produced only in the liver. ${ }^{6}$ The same authors reported that the RT-PCR analysis failed to detect any HRG mRNA in immune tissues, suggesting that the HRG found in immune cells must be acquired from plasma. This hypothesis is supported by a study of Olsen et al. that demonstrated the binding of HRG to T-cell lines and its active internalisation. ${ }^{7}$

We have previously described the association of a HRG-like molecule to purified rabbit skeletal muscle AMP deaminase (AMPD). ${ }^{8}$ In comparison with mature plasma HRG, the AMPD-associated variant probably contains a unique N-terminal extension. ${ }^{8}$ These results suggest that a possible mechanism for the production of this novel HRG isoform is the alternative splicing of the HRG primary transcript, forming an mRNA encoding a variant with a unique $\mathrm{N}$-terminus spliced onto the mature HRG polypeptide.

We have also provided the first evidence for the presence of this HRG-like protein in human skeletal muscle ${ }^{9}$ demonstrating the selective binding of an anti-HRG antibody to type IIB fibers and suggesting a preferential association of muscle HRG to the AMPD isoform $\mathrm{M}$ that is predominant in fast-twitch glycolitic fibers. Moreover, in a recent immunohistochemical analysis, performed on human skeletal muscle biopsies of patients affected by AMPD deficiency, we have shown a positive correlation between the HRG muscle content and the total determined AMPD activity. ${ }^{10} \mathrm{We}$ previously suggested a new model for skeletal muscle AMPD, a 1:1 molecular adduct in which two AMPD catalytic subunits assemble with
Correspondence: Prof. Antonio Raggi, Dipartimento di Scienze dell'Uomo e dell'Ambiente, Chimica e Biochimica Medica, Università di Pisa via Roma 55, 56126 Pisa, Italy.

Tel. +39.050 .2218679 Fax: +39.050 .2218660 .

E-mail: araggi@med.unipi.it

Key words: histidine-rich glycoprotein, skeletal muscle, AMP deaminase, HRG internalisation, immunocytochemistry.

Acknowledgements: this research was supported by a grant from the Italian MIUR.

Received for publication: 20 October 2010. Accepted for publication: 12 January 2011.

This work is licensed under a Creative Commons Attribution 3.0 License (by-nc 3.0).

(C)Copyright A.R.M. Sabbatini et al., 2011

Licensee PAGEPress, Italy

European Journal of Histochemistry 2011; 55:e6 doi:10.4081/ejh.2011.e6

two HRG subunits. ${ }^{11}$ However, the present data do not establish whether HRG permanently contributes to the structure of the enzyme or whether it simply binds the enzyme. Altogether, these observations prompted us to investigate the origin of skeletal muscle HRG in order to clarify whether this HRG variant is synthesized by the muscle cells or is acquired from plasma.

\section{Materials and Methods}

\section{Reagents}

Analytical grade reagents were used in all experiments. Phosphocellulose resin (P-11) was supplied by Whatman International (Maidstone, UK). Cell culture reagents were purchased from Biowittaker Cambrex (Walkersville, MD, USA).

\section{Tissue samples and rhabdomyosar- coma cell line}

Two human biopsy specimens, one from liver and the other from quadriceps femoris, were obtained from patients who underwent surgery for diagnostic purposes, following procedures approved by the University Hospital Ethics Committee, Pisa, Italy. Both tissue samples showed no histological or histochemical abnormalities on examinations.

The human embryonic rhabdomyosarcoma (RD) cell line was provided by the Lombardia and Emilia Experimental Zooprophylactic Institute (Brescia, Italy). The RD cells were cultured at $37^{\circ} \mathrm{C}$ in the presence of $5 \% \mathrm{CO}_{2}$ in 
the growth medium suggested by the provider and consisting of Minimum Essential Medium supplemented with $10 \%$ fetal bovine serum (FBS), non-essential amino acids, vitamins (B1, B2, B3, B6, folic acid, I-inositol, D-calcium pantothenate, choline chloride) and penicillinstreptomycin.

\section{Purification of histidine-rich-glyco- protein}

Human plasma HRG was purified according to the method of Rylatt et al. ${ }^{12}$ Briefly, a phosphocellulose column was first precycled according to the manufacturer's instructions and equilibrated with a loading buffer containing $0.5 \mathrm{M} \mathrm{NaCl}, 1 \mathrm{mM}$ EDTA, $1 \mathrm{mM}$ dithiothreitol (DTT) and $10 \mathrm{mM}$ sodium phosphate (pH 6.8). Human plasma from a healthy donor was collected by centrifugation at $1000 \mathrm{x} g$ for 20 min, and $\mathrm{NaCl}$ and EDTA were added to give a final concentration of $0.5 \mathrm{M}$ and $1 \mathrm{mM}$, respectively. The plasma was passed through the equilibrated column; the resin was first washed with loading buffer containing $0.8 \mathrm{M}$ $\mathrm{NaCl}$ and bound HRG was then eluted using loading buffer containing $2 \mathrm{M} \mathrm{NaCl}$. The purity of HRG preparations (>95\%) was evaluated by a 10\% SDS-PAGE and Western blot analysis. The concentration of HRG was determined using the Bio-Rad protein assay kit (Bio-Rad, Hercules, CA, USA) with BSA as standard.

\section{Screening of a cDNA expression library}

A human skeletal muscle cDNA expression library prepared in the Lambda ZAP II vector (Stratagene, La Jolla, CA, USA) was screened for cDNAs coding for the HRG protein according to Sambrook et al..$^{13}$ Briefly, approximately $2 \times 10^{6}$ plaques were screened by employing the rabbit anti-HRG antibody that we have previously described (1:10000) ${ }^{9}$ and a peroxidase labelled goat anti-rabbit IgG (1:5000) (Sigma, St. Louis, M0, USA) as secondary antibody. The nitrocellulose membranes were then developed with the Immun-Star HRP chemiluminescent kit (Bio-Rad).

\section{Primer design}

The sequences of the oligonucleotides used for the RT-PCR analysis are reported in Table 1. The paired primers HRG-1/HRG-2 and HRG3/HRG-4 were used to amplify the full length and the 974-1377 region of the HRG mRNA, corresponding to PCR products of $1691 \mathrm{bp}$ and 404 bp, respectively. The HRG-5 degenerate primer was designed to amplify, together with the HRG-2 primer, a 268 bp fragment corresponding to the mRNA region coding for the sequence recognized by the rabbit anti-HRG antibody that was used in this study.

Table 1. Sequences of the oligonucleotides used for the RT-PCR analysis and primer location.

\begin{tabular}{|c|c|c|c|c|c|c|}
\hline Oligonucleotides & $\begin{array}{l}\text { Nucleotide } \\
\text { positions }\end{array}$ & Polarity & \multicolumn{3}{|c|}{ Sequences } & References \\
\hline HRG-1 & $117-135$ & + & \multicolumn{3}{|c|}{ 5'TAACAAAATGAAGGCACTC-3' } & Koide et al..$^{3}$ \\
\hline HRG-2 & 1784-1807 & - & \multicolumn{3}{|c|}{ 5'AGTATGAAAGTAGGTTGAAAAGAA-3' } & Koide et al..$^{3}$ \\
\hline HRG-3 & $974-994$ & + & \multicolumn{3}{|c|}{ 5'-GATCATCATCATCCCCACAAG-3' } & Koide et al..$^{3}$ \\
\hline HRG-4 & $1358-1377$ & - & \multicolumn{3}{|c|}{ 5'-GGGTCACAAGGTCCATAGTC-3' } & Koide et al..$^{3}$ \\
\hline HRG-5 & $1540-1556$ & + & \multicolumn{3}{|c|}{ 5'-CCTGARGCCAAYTTYCC-3' } & Koide et al..$^{3}$ \\
\hline ACTIN-1 & $549-573$ & + & \multicolumn{3}{|c|}{ 5'-TCACCCACACTGTGCCCATCTACGA-3' } & Ponte et $_{\text {al. }}{ }^{14}$ \\
\hline ACTIN-2 & $819-843$ & - & \multicolumn{3}{|c|}{ 5'-CAGCGGAACCGGTCATTGCCAATGG-3' } & Ponte et al. ${ }^{14}$ \\
\hline HRG-1 & & & HRG-3 & HRG-4 & HRG-5 & HRG-2 \\
\hline
\end{tabular}

\section{RT-PCR analysis}

Total RNA from human skeletal muscle, human liver and RD cell line was extracted by using the TRIzol reagent (Invitrogen, Carlsbad, CA, USA). One $\mu \mathrm{g}$ of each sample was then submitted to Dnase I (Sigma) treatment according to the manufacturer's instructions, to remove contaminating genomic DNA. Reverse transcription was then performed at $42^{\circ} \mathrm{C}$ for $1 \mathrm{~h}$ as follows: $1 \mu \mathrm{g}$ of each sample was mixed with a solution containing $4 \mathrm{mM}$ $\mathrm{MgCl}_{2}, 50 \mathrm{mM} \mathrm{KCl}, 50 \mathrm{mM}$ Tris/HCl (pH 8.3), 1 mM each dNTP, $0.2 \mu \mathrm{g}$ Random Hexamer (Fermentas, York, UK), 20 U Ribonuclease inhibitor (Fermentas), 200 U RevertAid MMuLV reverse transcriptase (Fermentas) in a final volume of $20 \mu \mathrm{L}$.

The PCR reaction ( $25 \mu \mathrm{L}$ final volume) was carried out using $5 \mu \mathrm{L}$ of each cDNA sample in a solution containing $1.5 \mathrm{mM} \mathrm{MgCl}_{2}, 50 \mathrm{mM}$ $\mathrm{KCl}, 20 \mathrm{mM}$ Tris/HCl (pH 8.3), $0.2 \mathrm{mM}$ of each dNTP, $0.2 \mu \mathrm{M}$ of each primer and $1 \mathrm{U}$ of Platinum Taq DNA Polymerase (Invitrogen).

The amplification program to obtain the HRG full length cDNA was set to denature at $94^{\circ} \mathrm{C}$ for $30 \mathrm{~s}$, anneal at $52^{\circ} \mathrm{C}$ for $30 \mathrm{~s}$ and extend at $72^{\circ} \mathrm{C}$ for 2 min (for 35 cycles), whereas that to amplify the 974-1377 and 15401807 regions of HRG $\mathrm{cDNA}$ as well as the $\beta$ actin cDNA fragment was set at $94^{\circ} \mathrm{C}$ for $30 \mathrm{~s}$, at $52^{\circ} \mathrm{C}$ for $30 \mathrm{~s}$ and at $72^{\circ} \mathrm{C}$ for $30 \mathrm{~s}$ (for 40 cycles). The PCR products were separated on a $2 \%$ agarose gel and stained with ethidium bromide. The absence of contaminants was routinely checked by running control samples that contained no RNA, no reverse transcriptase or only the PCR reaction buffer. The quality of all RNA samples was tested by a $2 \%$ denaturing agarose gel and by RT-PCR analysis for human $\beta$-actin that gave the expected PCR product of $295 \mathrm{bp}$ in all samples.

\section{SDS-PAGE and Western blot analysis}

Electrophoresis in the presence of SDS was carried out in a $10 \%$ polyacrylamide gel as described by Laemmli. ${ }^{15}$ The RD cells extract used for SDS -PAGE was obtained as follows; $10 \times 10^{6} \mathrm{RD}$ cells were lysed using $50 \mu \mathrm{L}$ of a lysis buffer containing $10 \mathrm{mM}$ Tris/ $\mathrm{HCl}(\mathrm{pH}$ 7.6), $150 \mathrm{mM} \mathrm{NaCl}, 1 \mathrm{mM}$ EDTA, 1\% Triton X100 , plus a cocktail of protease inhibitors (Sigma): $12 \mu \mathrm{M}$ leupeptin, $100 \mu \mathrm{M}$ phenylmethylsulfonylfluoride, $10 \mu \mathrm{M}$ pepstatin A. Centrifugation $\left(10 \mathrm{~min}\right.$ at $12,000 \mathrm{x}$ g at $4^{\circ} \mathrm{C}$ ) allowed recovery of the cytosoluble protein fraction (cytosol).

Precision Plus Protein molecular weight standards (Bio-Rad) were used to calibrate the gel. After the SDS-PAGE, samples were electrotransferred to a nitrocellulose membrane. The blot was blocked using $5 \%$ non-fat milk in trisbuffered saline (TBS) for $1 \mathrm{~h}$ at room temperature and then treated with the previously described rabbit anti-HRG antibody ${ }^{9}$ diluted 1:5000 (v/v) in 5\% non-fat milk in TBS (1 h at room temperature). After washing with $0.5 \%$ Tween-20 in TBS, the blot was incubated with a goat anti-rabbit IgG peroxidase labelled polyclonal antibody (Sigma) diluted 1:10000 (v/v) in 5\% non-fat milk in TBS (1 h at room temperature) and then extensively washed with $0.5 \%$ Tween-20 in TBS and developed using the Immun-Star HRP chemiluminescent kit (BioRad). Controls included the omission of primary antibody and substitution of immune serum by pre-immune or non-immune rabbit serum.

\section{Treatment of rhabdomyosarcoma cells with human plasma histidine- rich-glycoprotein}

Five $\times 10^{4} \mathrm{RD}$ cells/well were plated in 8-well chamber-slides (Nalge Nunc International, Naperville, IL, USA) and incubated in complete 
growth medium ( $300 \mu \mathrm{L} /$ well) at $37^{\circ} \mathrm{C}$ with $5 \%$ $\mathrm{CO}_{2}$. After $24 \mathrm{~h}$, the medium was replaced with serum-free medium ( $200 \mu \mathrm{L} /$ well) to remove potentially cell-bound or cell-internalised bovine HRG derived from FBS contained in the complete culture medium. After further $30 \mathrm{~h}$ incubation, human plasma HRG (200 or 400 $\mu \mathrm{g} / \mathrm{mL}$ ) was added to the wells filled with a new serum-free medium containing $20 \mu \mathrm{M}$ zinc and the cells were kept at $37^{\circ} \mathrm{C}$ for further $15 \mathrm{~min}, 30 \mathrm{~min}$ or $4 \mathrm{~h}$. The cells were then washed twice with PBS, fixed in PBS containing $3.6 \%$ paraformaldehyde (20 min at room temperature) and submitted to immunocytochemistry for HRG. Control incubations were performed without the addition of HRG. Internalisation experiments were also carried out in the absence of zinc and also by incubating for $30 \mathrm{~min}$ the RD cells with $200 \mu \mathrm{g} / \mathrm{mL}$ HRG and $200 \mu \mathrm{g} / \mathrm{mL}$ heparin from porcine intestinal mucosa. All experiments were performed in duplicate and repeated four times. The cells used for the assays were in their exponential growth phase and showed a viability exceeding $95 \%$ even after the $30 \mathrm{~h}$ incubation with serum free medium, as determined by the Trypan blue exclusion test.

\section{Immunocytochemistry for histi- dine-rich-glycoprotein}

Pre-fixed cells were first washed with distilled water and then with PBS to remove free paraformaldehyde. Permeabilized cells were prepared by incubation with $0.2 \%$ Triton X-100 in PBS (10 $\mathrm{min}$ at room temperature) (Sigma). Permeabilized and unpermeabilized cells were then treated with a $0.06 \% \mathrm{H}_{2} \mathrm{O}_{2} / \mathrm{PBS}$ solution to quench the endogenous peroxidase activity and subsequently incubated at $37^{\circ} \mathrm{C}$ with 5\% swine serum (Dako, Glostrup, Denmark) to block non-specific reactivity. The samples were then incubated overnight at $4^{\circ} \mathrm{C}$ with the previously described ${ }^{9}$ rabbit anti-HRG polyclonal antibody (1:4000 in 5\% BSA/0.2\% gelatin-PBS). The detection protocol was carried out using biotinylated link antibodies and a streptavidin-peroxidase complex (LSAB kit, Dako). Among each step, slides were rinsed in Triton $(0.01 \%)$ and washed with PBS. The reaction was developed by incubating for $5 \mathrm{~min}$ the samples in a substrate-chromogen solution (3,3'-diaminobenzidine, Sigma), in the dark. After haematoxylin counterstaining, samples were dehydrated and mounted using DPX mountant (Fluka, Buchs, Switzerland). Negative controls were obtained omitting the primary antibody and incubating the specimens with $5 \%$ BSA $/ 0.2 \%$ gelatin-PBS or with pre-immune rabbit serum (1:4000 in 5\% BSA $/ 0.2 \%$ gelatin-PBS). All steps were performed at room temperature unless otherwise specified.

The number of immunoreactive cells was calculated by two independent observers out of a total of 500 randomly selected cells per sample. Statistical analysis of the differences in the positive cells number between samples was performed by the parametric Student t-test.

\section{Results}

\section{Studies to verify the expression of histidine-rich-glycoprotein mRNA in skeletal muscle}

With the purpose to isolate the full length cDNA sequence of the putative muscle specific form of HRG, a human skeletal muscle cDNA expression library was screened with a rabbit antibody, specific for the $\mathrm{C}$-terminal region of human plasma HRG, that has been shown to bind to type IIB fibers in human skeletal muscle. ${ }^{9,10}$ However, no positive clone could be identified following this procedure.

A human quadriceps femoris biopsy was processed for Western Blot analysis and immunohistochemistry using an anti-HRG antibody as previously described..$^{10} \mathrm{~A}$ positive reaction was observed by both techniques confirming, in this specimen, a clear prevalence of HRG in the type IIB fibers (results not shown). Total RNA was then extracted from the biopsy, reverse transcribed and submitted to PCR. The sequences of the oligonucleotides used for the RT-PCR analysis are reported in Table 1. The primers HRG-1 and HRG-2 were designed to amplify the HRG full length cDNA and HRG-3 together with HRG-4 to amplify a portion of the exon 7 encoding a histidine-rich region of the protein. In addition, primer HRG-2 together with the degenerate primer HRG-5 were used to amplify the cDNA sequence encoding the Cterminal region of plasma HRG that, according to our immunological analysis, is conserved in the muscle-specific form of HRG. ${ }^{9,10}$ No PCR product was obtained from muscle RNA under any of the above described conditions. When the above described RT-PCR analysis was performed on total RNA extracted from the human embryonal rhabdomyosarcoma RD cell line, the results were completely negative. In contrast, when human liver mRNA was used as positive control, three PCR products were obtained, corresponding to the HRG full length cDNA (1691 bp), to the 974-1377 cDNA region (404 bp) and to the sequence encoding the HRG C-terminal region (268 bp) (Figure 1).

\section{Internalisation of histidine-rich- glycoprotein by rhabdomyosarco- ma cells}

The use of a rabbit anti-HRG antibody allowed us to demonstrate the presence in

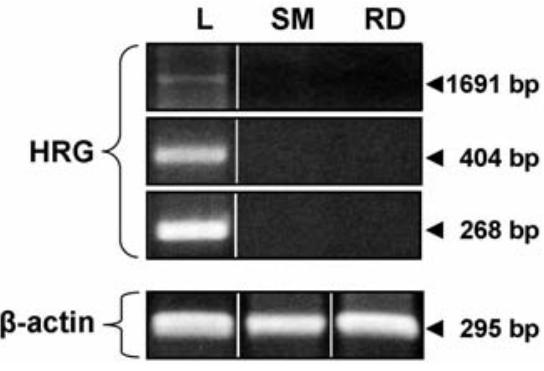

Figure 1. RT-PCR analysis. The indicated sizes of the amplified products correspond to the full length and to the 974-1377 and 1540-1807 regions of HRG cDNA. A control PCR for $\beta$-actin is also shown. $L$, human liver (control); SM, human skeletal muscle; $\mathrm{RD}, \mathrm{RD}$ cell line.

skeletal muscle of an immunoreactivity that gave rise to two bands with apparent molecular weight values of 95 and $70 \mathrm{kDa},{ }^{10}$ corresponding to those determined for the HRG component of skeletal muscle AMPD before and after deglycosylation. ${ }^{16}$ By Western blot analysis of the RD cells, carried out as described under Materials and Methods using the same antibody, no immunoreactive band could be detected (results not shown). In order to investigate whether HRG could be internalised by muscle cells, experiments were conducted in which the RD cells were incubated at $37^{\circ} \mathrm{C}$ with plasma HRG in the growth medium described under Materials and Methods with the addition of $20 \mu \mathrm{M} \mathrm{ZnCl}_{2}$, this concentration of zinc was used as it is the physiological blood concentration of zinc and has been shown to be the optimal one for HRG binding to most cell lines. ${ }^{17}$ Immunocytochemistry for HRG, performed at various times of incubation, was carried out on permeabilised or unpermeabilised cells to verify whether HRG was really internalised or simply passively absorbed on to the cell surface (Figure 2).

Whilst there was no apparent staining in the control RD cells incubated for $4 \mathrm{~h}$ in the absence of plasma HRG (Figure 2d), the presence of the protein in the growth medium caused its internalisation by the RD cells as evidenced by the time course of the immunoreaction performed on permeabilised cells. In particular, after 15 min incubation with $200 \mu \mathrm{g} / \mathrm{mL}$ HRG, only a few RD cells exhibited an immunoreactivity that was localised on the external side of the plasma membrane (Figure 2a). When the incubation was prolonged to $30 \mathrm{~min}$, an increase of the number of the reactive cells was observed $(7.6 \pm 1.3 \%)$. The immunoreactivity was still generally localised on the plasma membrane, although in a small number of cells immunore- 
activity could clearly be detected intracellularly (Figure 2b). When the incubation was carried out for $4 \mathrm{~h}$, the percentage of the positive RD cells increased significantly (16.6 $\pm 3.9 \%$; $\mathrm{P}=0.005)$. The intensity of the immunostaining was similar to that of 30 min samples, but appeared to be mainly localised at the cytoplasm level, although it could not be related to any distinct subcellular region or compartment (Figure 2c).

When the incubation of RD cells was carried out using a higher HRG concentration (400 $\mu \mathrm{g} / \mathrm{mL}$ ), the RD cells exhibited a stronger intensity of immunostaining but the timedependent internalisation of HRG as well as the proportion of HRG positive cells and the pattern of protein distribution resulted unchanged compared to that observed in the experiment carried out using $200 \mu \mathrm{g} / \mathrm{mL}$ HRG (Figures $2 \mathrm{e}$ and $2 \mathrm{f}$ ). No positive staining could be detected when the RD cells were incubated for $4 \mathrm{~h}$ in the presence of $200 \mu \mathrm{g} / \mathrm{mL}$ or 400 $\mu \mathrm{g} / \mathrm{mL}$ HRG without the addition of zinc (data not shown). When the immunocytochemistry was carried out on unpermeabilised RD cells incubated up to $4 \mathrm{~h}$ with HRG, the immunostaining was localised on the plasma membrane (insert of Figure 2c), without any apparent change of the localisation observed after 15 min incubation (insert of Figure 2a).

Altogether, the results obtained with permeabilised and unpermeabilised cells give evidence that HRG is internalised by the RD cells.

\section{Effect of heparin on histidine- rich-glycoprotein internalisation by rhabdomyosarcoma cells}

HRG has been reported to interact with the sulphated glycosaminoglycan (GAG) heparin with a 1:1 stoichiometry, to form a high affinity complex with a Kd of $7 \mathrm{nmol} / \mathrm{L} \cdot{ }^{18}$ Moreover, heparan sulphate proteoglycans are ubiquitously expressed on animal cell surfaces ${ }^{19}$ including muscle cells during myogenic differentiation. ${ }^{20}$ These observations suggest that the above described HRG uptake by the RD cells could occur through the binding of the protein to heparan sulphate GAGs localised on the cell surface. In order to examine this possibility, we studied the effect of the addition of heparin, at 6 fold higher ratio to HRG, to the incubation mixture used for the internalisation experiments.

After $30 \mathrm{~min}$ incubation with $200 \mu \mathrm{g} / \mathrm{mL}$ HRG in the presence of $200 \mu \mathrm{g} / \mathrm{mL}$ heparin, the percentage of immunostained RD cells $(4.2 \pm 0.5 \%)$ was significantly reduced $(\mathrm{P}=0.004)$ in comparison with that determined in the control samples incubated in the absence of heparin (Figure 3), clearly indicating an inhibitory effect of heparin on the uptake of HRG by the RD cells.
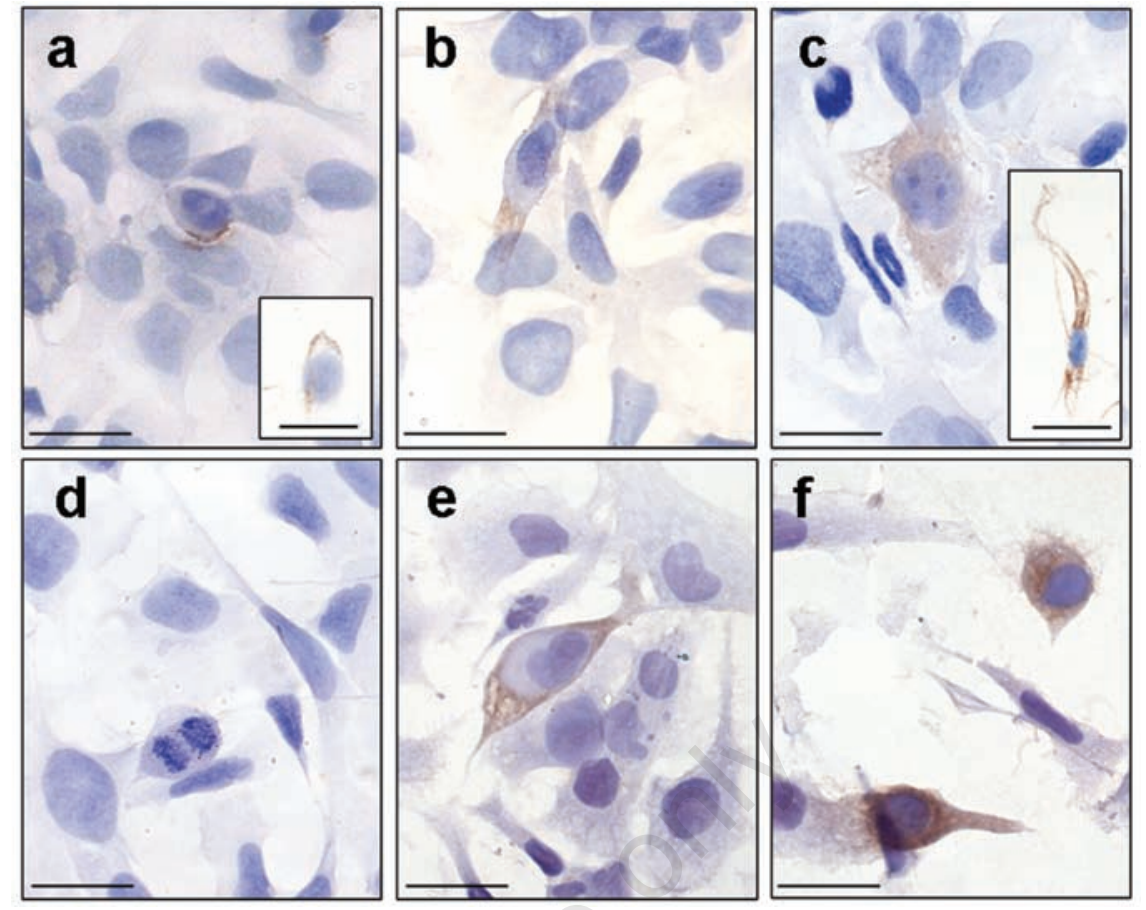

Figure 2. Internalisation of plasma HRG by RD cells. RD cells were incubated in a medium containing human plasma HRG, fixed in 3.6\% paraformaldehyde and submitted to immunocytochemistry performed on permeabilised or unpermeabilised cells, as described under Materials and Methods. The pictures show permeabilized $\mathrm{RD}$ cells incubated in the presence of $200 \mu \mathrm{g} / \mathrm{mL}$ HRG for $15 \mathrm{~min}(\mathrm{a}), 30 \mathrm{~min}$ (b) and $4 \mathrm{~h}$ (c), or in the presence of $400 \mu \mathrm{g} / \mathrm{mL}$ HRG for $30 \mathrm{~min}(\mathrm{e})$ and $4 \mathrm{~h}(\mathrm{f})$. The inserts of panels (a) and (c) show the immunoreactivity of unpermeabilized RD cells incubated in the presence of $200 \mu \mathrm{g} / \mathrm{mL}$ HRG for $15 \mathrm{~min}$ and $4 \mathrm{~h}$, respectively. (d) permeabilized RD cells incubated for $4 \mathrm{~h}$ in the absence of HRG. Scale bars: $25 \mu \mathrm{m}$.

\section{Discussion}

The characterization of HRG as a plasma protein is well established. ${ }^{21}$ We previously reported the existence of a HRG-like molecule associated with skeletal muscle AMPD..$^{8,9,16}$ In the present paper we have investigated the origin of skeletal muscle HRG in order to clarify whether this HRG variant is synthesized by the muscle cells or is acquired from plasma.

The observations reported in the present work indicate that skeletal muscle does not express plasma HRG mRNA, extending the negative results previously reported for this protein in several other tissues ${ }^{6}$ and thereby confirming that plasma HRG is synthesized only by parenchimal liver cells. ${ }^{3}$ No product was obtained when the RT-PCR analysis was performed on human skeletal muscle using primers specific to either the full length or an exon 7 region of plasma HRG mRNA.

The above observations do not exclude the possibility that a tissue specific form of HRG mRNA could be expressed by muscle, as our previous studies have shown that the HRG-like molecule isolated from purified rabbit skeletal muscle AMPD is an isoform of the plasma protein. ${ }^{8}$ This hypothesis can be rejected, however, since our investigation showed the total

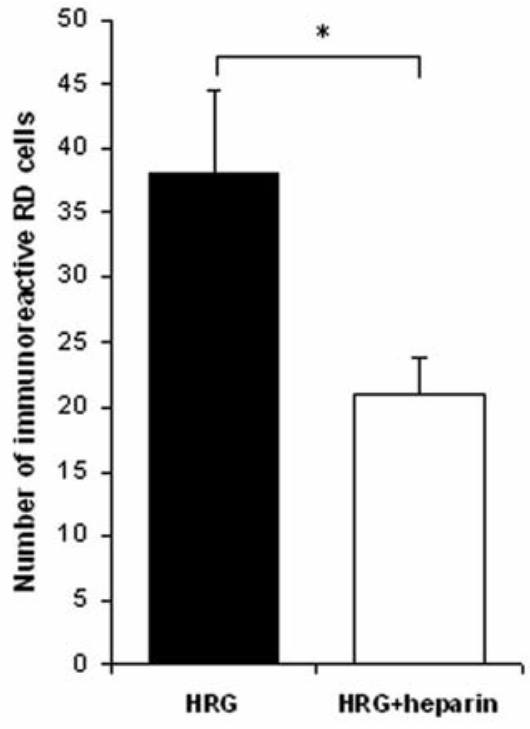

Figure 3. Effect of heparin on the internalisation of HRG by RD cells. Cells were incubated with $200 \mu \mathrm{g} / \mathrm{mL}$ plasma HRG, in the absence ( $\square$ ) or in the presence $(\square)$ of heparin $(200 \mu \mathrm{g} / \mathrm{mL})$, as described under Materials and Methods. The histograms represent the average number of immunoreactive cells, calculated from the observation of 500 randomly selected cells from each sample. Error bars represents the standard error. Differences were considered significant at $\mathrm{P}<0.01$. * $\mathrm{P}=\mathbf{0 . 0 0 4}$. 
absence of any muscle specific HRG mRNA. A human skeletal muscle cDNA expression library was screened with an anti-HRG antibody specific for the $\mathrm{C}$-terminal region of human plasma HRG, that has been shown to bind to type IIB fibers in human skeletal muscle,${ }^{9,10}$ but no positive clone could be identified. In addition, the RT-PCR analysis performed on total RNA extracted from human skeletal muscle with a degenerate primer, designed to amplify the mRNA region encoding for the Cterminal sequence of HRG recognized by the anti-HRG antibody, failed to detect any product. All the above negative results clearly indicate that the HRG-like molecule associated to skeletal muscle AMPD is not synthesized by human skeletal muscle fibers.

The present paper reports a further investigation that demonstrates that plasma HRG can be internalised by skeletal muscle fibers. The incubation of human RD cells in a medium containing human plasma HRG resulted in a progressive time-dependent uptake of the protein as detected by immunocytochemistry, establishing that muscle cells can internalise HRG.

Previous studies have shown that plasma HRG binds to many cell types, the localisation of the protein to the cell surface being generally mediated by heparan sulphate,,$^{17,22}$ although other cell surface receptors have been described including tropomyosin, ${ }^{23} \mathrm{FcR},{ }^{24}$ and ATP synthase. ${ }^{25}$ In contrast, the only study reporting the internalisation of HRG is that by Olsen et al. ${ }^{7}$ showing that HRG can be actively internalised by the human T-cell line MT4 via the interaction of the protein to cell surface GAGs.

It should be noted that only a limited number of RD cells were able to bind and internalise HRG. After $4 \mathrm{~h}$ incubation with $200 \mu \mathrm{g} / \mathrm{mL}$ HRG, the percentage of immunoreactive RD cells was $16.6 \%$. When the uptake experiments were carried out using a higher HRG concentration $(400 \mu \mathrm{g} / \mathrm{mL})$, a stronger immunoreactivity could be detected but the proportion of positive cells remained unchanged; this observation is totally consistent with that reported for MT4 cells (15-20\%) after a similar treatment. ${ }^{7}$ We also observed an inhibitory effect of heparin on the uptake of HRG, strongly suggesting that the protein binds to RD cells via GAGs. However, an excess of heparin caused only a $50 \%$ reduction of the HRG binding to RD cells, whereas a percentage of inhibition higher than $90 \%$ was previously reported for the HRG binding to the T-cells. ${ }^{7}$ Although our data can not exclude a heparan sulphate-independent binding of HRG to RD cells, the limited inhibitory effect of heparin on the HRG binding could be explained by the different cell type used in our study. RD cells are poorly differentiated since they are an embryonic rhabdomyosarcoma cell line; it is therefore possible that more highly differentiated cells might demonstrate a more efficient uptake of the protein. Crucial events in myogenesis rely on the highly regulated spatiotemporal distribution of cell surface heparan sulphate proteoglycans to which growth factors are associated; in addition, the composition of GAG species is modified during myogenic differentiation, in particular heparan sulphate levels that are increased during this process. ${ }^{20}$ Moreover, heparan sulphate species from different tissue sources differ in charge and domain organisation. ${ }^{26-28}$ Further studies are in progress to evaluate the role of myogenic differentiation on the capability of HRG internalisation.

HRG is known to bind a variety of ligands, including heme and divalent cations. ${ }^{29}$ It has been established that HRG from rabbit serum binds $\mathrm{Hg}^{2+}, \mathrm{Cu}^{2+}, \mathrm{Zn}^{2+}, \mathrm{Ni}^{2+}, \mathrm{Cd}^{2+}, \mathrm{Co}^{2+}$ in descending order of binding affinity and with an apparent stoichiometry of $10\left(\mathrm{Cu}^{2+}, \mathrm{Co}^{2+}\right.$, $\mathrm{Ni}^{2+}$ and $\left.\mathrm{Hg}^{2+}\right)$ to $20\left(\mathrm{Zn}^{2+}\right.$ and $\left.\mathrm{Cd}^{2+}\right)$ metal ions bound per HRG molecule. ${ }^{30,31}$ Altogether, these results may be interpreted as an indication that most of such a large number of metal binding sites are non-specific and most of the zinc is simply adventitiously bound. More positive conclusions can be reached by taking in consideration the available data on the characterization of the zinc binding site of HRG. The interaction between plasma HRG and $\mathrm{Zn}^{2+}$ is abolished when histidine residues are chemically removed from HRG, supporting the model that histidine residues are essential for $\mathrm{Zn}^{2+}$ binding. ${ }^{30}$ We previously reported that the HRG molecule associated with skeletal muscle AMPD can be isolated from the enzyme by zinc-affinity chromatography. ${ }^{16}$ In a recent study, we have characterized the zinc-binding site of the isolated HRG. X-ray absorption spectroscopy analysis of a 2:1 zinc-HRG complex has shown that zinc is bound to the protein in a dinuclear cluster where each $\mathrm{Zn}^{2+}$ ion is coordinated to histidine ligands and the sulfur donated by a cysteine. On the basis of this work, we suggested that Cys-294 that seems to belong to a loop connecting a Pro-rich region to a His-rich region is the most probable candidate for zinc ligation. ${ }^{11}$

The vast majority of $\mathrm{Zn}^{2+}$ in the blood $(\sim 20$ $\mu \mathrm{M})$ is bound to human serum albumin since the serum concentration of this protein is higher than that of HRG $(\sim 250 \mu \mathrm{M}$ vs. 2.5 $\mu \mathrm{M}) .^{31}$ Therefore, it can be concluded that HRG has no role in the chelation of $\mathrm{Zn}^{2+}$ and other metals to protect blood and endothelial cells from the otherwise toxic concentrations present in the circulation. On the contrary, the exceptionally high level of zinc in skeletal muscle (1 mM) coupled to the very low cyto- plasmic free zinc concentration (about $0.1 \mathrm{nM}$ ) suggests that HRG could exert a central role for the physiological functions of $\mathrm{Zn}^{2+}$ inside muscle cells, making intracellular free zinc available for specific metalloproteins. The binding of $\mathrm{Zn}^{2+}$ by the isolated HRG component of skeletal muscle AMPD as well as by plasma HRG exhibits a positive cooperativity so that the apparent $\mathrm{Kd}_{\mathrm{HRG}}(1-4 \mu \mathrm{M})$ may understimate its true affinity.11,31 Interestingly, the characterization of skeletal muscle AMPD as a zinc metalloenzyme was previously report$\mathrm{ed}^{32,33}$ and the evidence of a dinuclear zinc site in the catalytic subunit of the rabbit enzyme has recently been provided. ${ }^{34}$

The complete separation of the HRG molecule associated with rabbit skeletal muscle AMPD induced a marked reduction in the solubility of the enzyme, strongly suggesting a role of HRG in increasing the stability of the molecular structure of the enzyme. Moreover, AMPD fractions with a different stoichiometry of association between HRG and the catalytic subunit showed different kinetic behaviour indicating that the HRG component is also critical for a stable AMPD activity. ${ }^{16}$ On the basis of these results, we concluded that the HRG component of AMPD behaves as a zinc metallochaperone. ${ }^{11,34}$ In this view, HRG may enhance the stability of AMP deaminase in vivo through insertion of zinc or by modulating the availability of intracellular zinc. The evidence given by the present paper, that plasma HRG can be internalised by muscle cells in the presence of $20 \mu \mathrm{M}$ zinc but not in its absence, strengthens the hypothesis that HRG could play a role as metallochaperone for the trafficking of $\mathrm{Zn}^{2+}$ ions from plasma to muscle cells.

We have also previously suggested that the reported rapid disappearance of AMPD from the circulation due to the binding and internalization of the enzyme by the hepatocytes, ${ }^{35}$ is promoted by the interaction of the HRG component of AMPD with cell surface heparan sulphate. ${ }^{8}$ On the basis of the observations of the present paper, such a phenomenon can reasonably be extended to the partitioning of the enzyme between plasma and skeletal muscle cells. In comparison with plasma HRG, the muscle variant has been reported to contain a unique $\mathrm{N}$-terminal extension that has been ascribed to a possible alternative splicing of the HRG primary transcript. ${ }^{8}$

The available data are not sufficient to hypothesize any role played by the $\mathrm{N}$-terminal extension neither for the reported predominance of muscle HRG in type IIB fibers ${ }^{9}$ nor for the docking of this protein with skeletal muscle fibers. To address these issues, is our intention to extend the internalisation experiments to the use of the HRG variant isolated from skeletal muscle. 


\section{References}

1. Morgan WT, Koskelo P, Koenig H, Conway TP. Human histidine-rich glycoprotein. II. Serum levels in adults, pregnant women and neonates. Proc Soc Exp Biol Med 1978;158:647-51.

2. Jones AL, Hulett MD, Parish CR. Histidinerich glycoprotein: A novel adaptor protein in plasma that modulates the immune, vascular and coagulation systems. Immunol Cell Biol 2005;83:106-18.

3. Koide T, Foster D, Yoshitake S, Davie EW. Amino acid sequence of human histidinerich glycoprotein derived from the nucleotide sequence of its cDNA. Biochemistry 1986;25:2220-5.

4. Sia DY, Rylatt DB, Parish CR. Anti-self receptors V. Properties of a mouse serum factor that blocks autorosetting receptors on lymphocytes. Immunology 1982;45:207-16.

5. Leung LL, Harpel PC, Nachman RL, Rabellino EM. Histidine-rich glycoprotein is present in human platelets and is released following thrombin stimulation. Blood 1983;62:1016-21.

6. Hulett MD, Parish CR. Murine histidinerich glycoprotein: cloning, characterization and cellular origin. Immunol Cell Biol 2000;78:280-7.

7. Olsen HM, Parish CR, Altin JG. Histidinerich glycoprotein binding to T-cell lines and its effect on T-cell substratum adhesion is strongly potentiated by zinc. Immunology 1996;88:198-206.

8. Ranieri-Raggi M, Montali U, Ronca F, Sabbatini A, Brown PE, Moir AJG, et al. Association of purified skeletal-muscle AMP deaminase with a histidine-prolinerich glycoprotein-like molecule. Biochem J 1997;326:641-8.

9. Sabbatini ARM, Ranieri-Raggi M, Pollina L, Viacava P, Ashby JR, Moir AJG, et al. Presence in human skeletal muscle of an AMP deaminase-associated protein that reacts with an antibody to human plasma histidine-proline-rich glycoprotein. J Histochem Cytochem 1999;47:255-60.

10. Sabbatini ARM, Toscano A, Aguennouz M, Martini D, Polizzi E, Ranieri-Raggi M, et al. Immunohistochemical analysis of human skeletal muscle AMP deaminase deficiency. Evidence of a correlation between the muscle HPRG content and the level of residual AMP deaminase activity. $\mathrm{J}$ Muscle Res Cell Motil 2006;27:83-92.

11. Mangani S, Meyer-Klaucke W, Moir AJG, Ranieri-Raggi M, Martini D, Raggi A. Characterization of the $\mathrm{Zn}$ binding site of the histidine-proline-rich glycoprotein associated with rabbit skeletal muscle AMP deaminase. J Biol Chem 2003;278:
3176-84.

12. Rylatt DB, Sia DY, Mundy JP, Parish CR. Autorosette inhibition factor: isolation and properties of the human plasma protein. Eur J Biochem 1981;119:641-6.

13. Sambrook J, Fritsch EF, Maniatis T. Molecular Cloning. A laboratory manual. 2nd ed. 1989, Cold Spring Harbor Laboratory Press, Cold Spring Harbor, NY, USA.

14. Ponte P, Ng SY, Engel J, Gunning P, Kedes L. Evolutionary conservation in the untranslated regions of actin mRNAs: DNA sequence of a human $\beta$-actin cDNA. Nucleic Acids Res 1984;12:1687-96.

15. Laemmli UK. Cleavage of structural proteins during the assembly of the head of bacteriophage T4. Nature 1970;227: 680-5.

16. Ranieri-Raggi M, Martini D, Sabbatini ARM, Moir AJG, Raggi A. Isolation by zincaffinity chromatography of the histidineproline-rich glycoprotein molecule associated with rabbit skeletal muscle AMP deaminase. Evidence that the formation of a protein-protein complex between the catalytic subunit and the novel component is critical for the stability of the enzyme. Biochim Biophys Acta 2003;1645:81-8.

17. Jones AL, Hulett MD, Parish CR. Histidinerich glycoprotein binds to cell-surface heparan sulfate via its $\mathrm{N}$-terminal domain following $\mathrm{Zn} 2+$ chelation. J Biol Chem 2004;279:30114-22.

18. Lijnen HR, Hoylaerts M, Collen D. Heparin binding properties of human histidinerich-glycoprotein. Mechanism and role in the neutralization of heparin in plasma. $\mathrm{J}$ Biol Chem 1983;258:3803-8.

19. Bernfield M, Götte M, Park PW, Reizes 0, Fitzgerald ML, Lincecum J, et al. Functions of cell surface heparan sulfate proteoglycans. Annu Rev Biochem 1999;68:729-77.

20. Barbosa I, Morin C, Garcia S, Duchesnay A, Oudghir M, Jenniskens G, et al. A synthetic glycosaminoglycan mimetic (RGTA) modifies natural glycosaminoglycan species during myogenesis. J Cell Sci 2005;118:253-64.

21. Heimburger N, Haupt H, Kranz T, Baudner S. Human serum proteins with high affinity to carboxymethylcellulose. II. Physicochemical and immunological characterization of a histidine-rich 3,8S-2-glycoprotein (CM-protein I). Hoppe-Seylers Z Physiol Chem 1972;353:1133-40.

22. Parish CR, Rylatt DB, Snowden JM. Demonstration of lymphocyte surface lectins that recognize sulphated polysaccarides. J Cell Sci 1984;67:145-58.

23. Guan X, Juarez JC, Qi X, Shipulina NV, Shaw DE, Morgan WT, et al. Histidine-proline-rich glycoprotein (HPRG) binds and transduces anti-angiogenic signals through cell surface tropomyosin on endothelial cells. Thromb Haemost 2004;92:403-12.

24. Gorgani NN, Altin JG, Parish CR. Histidine-rich glycoprotein regulates the binding of monomeric IgG and immune complexes to monocytes. Int Immunol 1999;11:1275-82.

25. Ohta T, Ikemoto Y, Usami A, Koide T, Wakabayashi S. High affinity interaction between histidine-rich glycoprotein and the cell surface type ATP synthase on Tcells. Biochim Biophys Acta 2009;1788: 1099-107.

26. Ledin J, Staatz W, Li JP, Götte M, Selleck S, Kjellén L, et al. Heparan sulfate structure in mice with genetically modified heparan sulfate production. J Biol Chem 2004;279: 42732-41.

27. Maccarana M, Satura Y, Tawada A, Yoshida $\mathrm{K}$, Lindahl U. Domain structure of heparan sulfates from bovine organs. J Biol Chem 1996;271:17804-10.

28. Vanwildemeersch M, Olsson AK, Gottfridsson E, Claesson-Welsh L, Lindahl U, Spillmann D. The anti-angiogenic His/Pro-rich fragment of Histidine-rich glycoprotein binds to endothelial cell heparan sulfate in a $\mathrm{Zn} 2+$-dependent manner. J Biol Chem 2006;281:10298-304.

29. Morgan WT. Human serum histidine-rich glycoprotein. I. Interactions with heme, metal ions and organic ligands. Biochim. Biophys. Acta 1978;535:319-33.

30. Morgan WT. Interactions of the histidinerich glycoprotein of serum with metals. Biochemistry 1981;20:1054-61.

31. Guthans SL, Morgan WT. The interaction of zinc, nickel and cadmium with serum albumin and histidine-rich glycoprotein assessed by equilibrium dialysis and immunoadsorbent chromatography. Arch Biochem Biophys 1982;218:320-8.

32. Raggi A, Ranieri M, Taponeco G, RoncaTestoni S, Ronca G, Rossi CA. Interaction of rat muscle AMP aminohydrolase with chelating agents and metal ions. FEBS Lett 1970;10:101-4.

33. Zielke CL, Suelter CH. Rabbit muscle adenosine 5'-monophosphate aminohydrolase. Characterization as a zinc metalloenzyme. J Biol Chem 1971;246:2179-86.

34. Mangani S, Benvenuti M, Moir AJG, Ranieri-Raggi M, Martini D, Sabbatini ARM, et al. Characterization of the metallocenter of rabbit skeletal muscle AMP deaminase. Evidence for a dinuclear zinc site. Biochim Biophys Acta 2007;1774:31222.

35. Husic DH, Suelter CH. Circulatory clearance, internalization and degradation of muscle AMP aminohydrolase. J Biol Chem 1984;259: 4359-64. 